\title{
UTOPISMO PASTORIL EN LA POESÍA DIECIOCHESCA: LA ÉGLOGA DE TOMÁS DE IRIARTE
}

\author{
Juan CANO BALLESTA \\ University of Virginia
}

Desde antiguo solían decir los retóricos que los poetas mienten o fingen. Para ellos la verdad poética venía a significar copia o imitación de una realidad exterior y previa. Mentira o ficción era la creación de una realidad propia y autónoma, fruto de las facultades imaginativas y de la fantasía. Verdad y mentira venían a ser las dos grandes vetas de todo arte: imitación más o menos fiel e imaginación más o menos desbordada, realismo en sus varios grados y creación total.

En los retóricos renacentistas el tópico de la mentira literaria era parte integrante de toda una red preceptiva que trataba de regular los elementos imaginativos de la obra poética estableciendo jerarquías y salvando siempre su propiedad y verosimilitud. Antonio García Berrio lo ha formulado así:

La literatura, el arte en general, se mueve en una escala de valores en la que el valor máximo es la belleza; de aquí que entre lo verdadero imperfecto y limitado, y lo falso perfecto, se prefiera siempre lo segundo, siempre que el poeta sea capaz de dotarlo de la necesaria dosis de verosimilitud (174).

La preceptiva renacentista está con todo ello haciendo dos cosas: a) justificando la fantasía y dándole alas, si bien un poco recortadas, en sus vuelos de ficción, y b) considerando la mentira poética o ficción como una verdad más profunda y universal que la de la historia, con la cual no obstante conserva un lazo interior irrompible. Está elevando la categoría estética de todo elemento imaginativo, precisamente porque esas mentirosas ficciones que se forja la imaginación — de las cuales el género bucólico es un ejemplo destacado - pueden ser portadoras de visiones más hondamente verdaderas, más universales y trascendentes. Pero aún en este caso 
se está tratando de justificar la creación poética por su relación más o menos intensa con un mundo de realidades más profundas. Hans Blumenberg lo anota con perspicacia:

En la historia de nuestra teoría estética nunca se ha abandonado seriamente el intento de legitimar la creación estética a partir de su relación con la realidad (10).

El género pastoril es, por definición, la creación de una utopía. Así lo entiende Luzán cuando dice en su Poética:

La materia y asunto de esta especie de Poesía son las costumbres de los Pastores, sus amores, sus contiendas, sus ganados y su vida feliz, libre de ambición y de fausto (lib III, cap XVI,427).

Pero este mundo ideal, construido con las frágiles telas de araña de la fantasía, conserva siempre vigente y tenso ese "cordón umbilical" que lo une al mundo de la realidad y de la historia. Es esta dialéctica entre realidad y ficción, entre mundo objetivo y utopismo arcádico, lo que intento estudiar.

En la ya numerosa investigación sobre la poesía del siglo XVIII se ha venido poniendo de relieve la importancia de la faceta utilitaria, el interés por el progreso económico, las ciencias, las artes, la industria, la agricultura, el lenguaje científico especializado. Hay toda una serie de motivos que prueban la atención muy particular que se prestaba a la realidad próxima cotidiana, al monumento que se acababa de inaugurar, al edificio recién construido, a la evocación de un arquitecto renombrado, etc. Esto ha estado alejando todo posible interés por un tipo de composición que, al presentarse como égloga, se situaba, de principio, en la vertiente evasiva de las letras y tendía a pintar los mundos idílicos de un viejo género. Un análisis cuidadoso creo que nos puede dar una imagen bastante distinta.

La Égloga de Tomás de Iriarte "La felicidad de la vida del campo", presentada a la Real Academia en 1779, podría ser considerada como paradigma de este juego entre ficción utópica y realidad, en que se mueven ciertos géneros de la poesía dieciochesca. Es cierto que durante décadas esta égloga ha sido ignorada por la crítica como obra de menor importancia. Cotarelo y Mori incluso la considera inferior en calidad poética a la silva "La felicidad en el campo", compuesta hacia 1773, de donde Iriarte adopta varios pasajes para este poema (221). En el esfuerzo generalizado de los últimos lustros por revalorizar la creación artística dieciochesca, no podía quedar olvidada esta obra de Tomás de Iriarte, poeta canario conocido y celebrado en varias lenguas y países europeos como excelente fabulista. La Egloga recibió un accessit de la Real Academia Española y fue publicada por la misma en 1780 . 


\section{Utopismo pastoril}

La literatura pastoril había gozado durante siglos del favor generalizado de los lectores, como con abundancia de datos ha sabido exponer Francisco López Estrada, pintando bellas escenas que significaban la fuga de la realidad hacia una región arcádica. En el movimiento de los Ilustrados salmantinos con su intento restaurador de un nuevo Siglo de Oro, "lo neoclásico - dice De la Flor-, entendido aquí como el estilo que pone en circulación la Ilustración, constituye un haz de revivals" (135).Entre éstos el renacer de la bucólica es uno de los más destacados. El poema que nos ocupa es una égloga, pero se enriquece con cuestiones candentes de la investigación crítica de su tiempo. Tiene mucho de ensayo filosófico, de visión crítica del campo y de la polis, e incluso de investigación sociológica, confirmando, en parte, algunos de los hallazgos de la crítica. Alberto Navarro González considera la Égloga "escrita con mentalidad de economista y sociólogo" (14) y Quintana la describe como "una lección de economía doméstica y aún de moral" (Cotarelo y Mori 226). Estos juicios formulados generalmente con la connotación de rebajar la calidad lírica y poética de Iriarte, los aceptamos como índices de un hecho, mientras que, siguiendo valoraciones de expertos como Russell Sebold y Guillermo Carnero, creemos que los temas científicos, económicos, el progreso, la técnica, no estaban reñidos con la poesía: "la ciencia - [lejos de ser un elemento antipoético] - es poesía en el siglo XVIII. Mas a la vez la poesía es ciencia" (Sebold, Descubrimiento 20). Saint-Lambert escribía en su Discours préliminaire a Les Saisons:

Le langage de la philosophie, reçu dans le monde, a pu l'être dans la poésie; on a pu entreprendre des pöemes qui demandent une connaissance variée de la nature (De Nardis 128)

Será el siglo XIX con su positivismo y cientifismo y, sobre todo, los poetas simbolistas y bohemios con su búsqueda de lo misterioso, lo irracional, lo vaporoso y lo enfermizo, los que crearán esta pertinaz contraposición entre poesía y ciencia como conceptos irreconciliables, en que hoy nos movemos. Pero el siglo XVIII disfruta todavía de la ingenuidad de considerar poético todo lo bello, lo verdadero y lo útil. Recordemos los tratados de agricultura en verso, como las Geórgicas de Virgilio, cuya huella humanística tan de cerca se seguía. La verdad es el blanco final de toda ciencia y también de la poesía del siglo XVIII. El racionalismo dieciochesco no podía entregar su creación poética a los impulsos ciegos de la inspiración; la poesía es, como se ha dicho, un rapto de la mente, pero racional.

El poema "La felicidad de la vida del campo"' se desarrolla dentro del

1. Cito la Égloga de Tomás de Iriarte indicando los versos y refiriéndome a la edición de Leopoldo Augusto de Cueto, Poetas líricos del siglo XVIII, II, Madrid, BAE, vol. 63, 1871, 46-50. 
marco bucólico, beneficiándose de su prestigio y ateniéndose a las fórmulas del género pastoril. El diálogo entre dos pastores, cuyos nombres Albano y Sileno no pueden responder más de lleno a esta tradición bucólica, se inicia al amanecer:

El rostro de la aurora anuncia que de Febo la venida acaso tardará más de una hora (vv. 79-81)

Y se cierra a la hora del atardecer siguiendo la vieja convención del género:

Pero ya soy molesto, y la sombría tarde en este lugar nos hallaría, si inútil no creyera... (vv.501-03)

Muchas son las viejas fórmulas, de raigambre clásica o renacentista, que nos suenan a conocidas:

¿Adonde presuroso te encaminas, Sileno amigo? (vv. 1-2)

¡Oh, salgan falsas las sospechas mías! (v. 16)

Es injusta la feroz crítica de Juan Pablo Forner cuando acusa a Iriarte de no saber lo que és una égloga (Cox 32 ). El poeta canario conoce perfectamente el género y orienta su poema hacia el enfrentamiento campo-ciudad forzado por la Academia, que había elegido este tema para el concurso y que encaja bien en el género pastoril y en su horizonte de expectativas. Cuando los autores griegos y latinos querían imaginarse una existencia paradisíaca, no pensaban en las ciudades, a pesar de que las había muy bellas en la Grecia antigua o en el vasto imperio romano. Hesiodo (siglo VIII a. C.) al tratar de imaginarse en Los trabajos y los días el mundo ideal de la Edad Dorada, lo sitúa "en los confines de la tierra", en las Islas de los Benditos, lugar alejado de los centros de civilización, y lo describe de este modo:
...disfrutaban toda clase de bienes:
pues la fértil tierra les daba sin esfuerzo
fruto abundante y sin límite.
Vivían tranquila y pacíficamente en su tierra
dueños de abundantes ganados
y amados por los benditos dioses (Giamatti 18)

Ejemplos parecidos podríamos aducir en toda la tradición desde Teócrito, Píndaro, Virgilio, Horacio, Ovidio, Prudencio, San Isidoro, Sannazaro, Garcilaso y Fray Luis de León, que buscan inquietos las delicias de un rincón feliz, de armonía y paz, y lo sitúan inequívocamente lejos de los 
centros urbanos, que consideran poseídos por la ambición del poder, las envidias y la sed de dinero.

Este viejo utopismo, recogido por la tradición pastoril, queda plenamente incorporado a la Égloga de Iriarte a través de un complejo sistema de signos y alusiones que iremos desmenuzando. Es Albano, "sujeto distinguido", que tras conocer la ciudad decidió volver al campo, quien se recrea en describir las delicias de contemplar las fértiles campiñas y el pequeño jardín junto a la rústica vivienda:

Un cultivado huerto, en que florecen

la delicada rosa y el jacinto,

$y$ los jazmines entre murtas crecen,

mezclándose con salvias y alhelíes,

blancos lirios, claveles carmesíes (v. 126-30)

Evoca la bella estación primaveral con sus cumbres nevadas que se derriten para regar los umbrosos valles, el canto del ruiseños, o el retozar de los blancos corderillos. Pero Sileno se encarga de desaher el viejo tópico (las "gratas imágenes") de la utopía pastoril, creada por "el ingenioso coro de los poetas" que siguen soñando con la edad áurea:

\section{A quien no se figura}

que espiró la feliz edad del oro

en que del campo, fértil sin cultura,

se hallaba el hombre dueño

al despertar de un reposado sueño,

$y$, sin salir de incógnitas florestas,

pasaban con sus ninfas los pastores

enteros días en alegres fiestas,

en versos, danzas, músicas y amores...(vv. 194-202)

Las delicias de la utopía pastoril son evocadas con bellas pinceladas y con abundancia de datos. La prestigiosa cultura clásica, reinterpretada y revivida por el Renacimiento, impregna inevitablemente nuestra percepción de este viejo mito. No podemos hablar, ni hoy ni en el siglo XVIII, de tranquilidad campestre sin que, de alguna manera, no nos resuene el eco del "Cuán bienaventurado / aquel puede llamarse" de Garcilaso, o recordemos el "Qué descansada vida" de Fray Luis, o nos vengan a la memoria los versos de Lope: "De mis soledades vengo / a mis soledades voy". Con ellos va toda una poderosa carga de emociones y recuerdos. Iriarte lo logra con unas pocas pinceladas, pero esenciales, al evocar: a) un lugar en medio de la naturaleza y en armonía con ella; b) una economía agrícola en un clima ideal; c) la abundancia de frutos naturales sin necesidad de trabajo ("fértil sin cultura"); d) el ser humano disfrutando de un tranquilo y no perturbado reposo ("al despertar de un reposado sueño"); e) la entrega al ocio y al 
disfrute feliz de la danza, la música, la poesía y el amor, en un mundo que escapa a la realidad para fundirse con las míticas ninfas.

Pero no olvidemos que Sileno evoca todo este bello ambiente pastoril para calificarlo de "ficciones hechiceras" (v. 204) y rechazarlo como "pomposas descripciones, hijas de la fecunda fantasía" (v. 209-10). La inmediata respuesta de Albano no insiste en la vertiente utópica del mito, sino que acentúa la faceta pragmática y práctica de la realidad campestre. Pero no sin refutar antes, pasando de lleno al plano estético, la osada afirmación de Sileno de que "la poesía / de la verdad los límites excede" (v. 213). ¡No! dice Albano, las maravillas de la naturaleza son tales que la poesía apenas si se les acerca, ya que son inefables ("pintar milagros que pintar no puede" v. 215). ¿No está Iriarte suscitando una emoción de la naturaleza de matiz semirromántico, mientras define una poética casi simbolista al recordar los misterios de la naturaleza como algo inefable, que la poesía en vano intenta captar? Resulta sorprendente el tropezarnos en estos versos con sensaciones que no nos parecían concebibles en el siglo ilustrado. La maravillosa belleza visual de un ocaso con sus matizados colores ¿no preludia visiones o cuadros impresionistas?:

\author{
¿Finge o pondera acaso \\ cuando del claro sol nos representa \\ el majestuoso aspecto en el ocaso? \\ ¿Describirá los bellos tornasoles \\ que le ocultan la faz, y que su ausencia \\ suplen con encendidos arreboles? \\ ¿Ni aquella inimitable diferencia \\ de figuras que forman los cejales \\ cuando con mil extraños maridajes \\ de colores se esmalta el horizonte, \\ y de pálidos rayos alumbrado, \\ ya no parece verde el verde monte, \\ y el río, que era plata, ya es dorado (vv. 217-29)
}

Yo diría que Iriarte está evocando un ocaso muy próximo a los que solían pintar un siglo después los impresionistas: la ilusión de movimiento y los objetos desfigurados por la luz ("aquella inimitable diferencia / de figuras que forman los celajes"); las fugaces y efímeras mezclas de colores ("Cuando con mil extraños maridajes / de colores se esmalta el horizonte"); la difuminación de los colores primarios en infinitos matices y tonos cromáticos: "Ya no parece verde el verde monte, / y el río, que era plata, ya es dorado". Las ilusiones ópticas creadas por la luz al atardecer, que los impresionistas llevaron al lienzo, ya son percibidas por un poeta sensible y culto del siglo XVIII. 


\section{Llamada a la realidad}

Pero estos mundos de evasión lírica y pastoril se engarzan en la Égloga con urgentes llamadas a la realidad próxima, a ideales filosóficos precisos, a la exaltación de valores prácticos e inmediatos que sentía muy vivamente el hombre de la Ilustración. Lejos de moverse en el mundo de la ficción y de la fantasía, son versos que contienen - en frase del mismo Iriarte"tanta verdad como si fueran prosa". Con ello está descendiendo del plano imaginativo al real y poniendo de relieve una faceta muy valiosa de su poesía y de esta égloga en particular.

Albano se declara dispuesto a abandonar esas exageraciones ("ideas... abultadas o falaces") de la utopía pastoril para descender a argumentos "más serios y eficaces" ( v. 239). Lo interesante es que, superando la falacia utopista, considera la realidad de la vida rústica en su urgente actualidad. Por encima del lugar común sabe el poeta percibir la belleza del paisaje en sí mismo. Eso es lo que encontramos en la Égloga de Iriarte como veíamos hace un momento en la impresionista puesta de sol. Por encima del tópico, de la fórmula estereotipada, hallamos también descripciones del paisaje real, emoción de la naturaleza, pintura de unos montes y valles directamente observados. Junto a la alusión convencional y abstracta al sucederse de las estaciones nos tropezamos con la visión objetiva y plenamente vivida de una experiencia próxima:

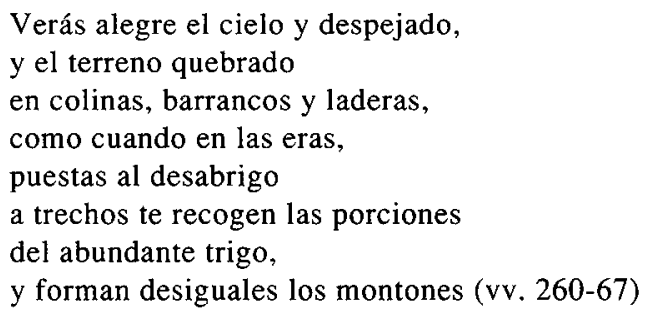

O la visión del Guadarrama con sus nieves, pinos y maleza, los bajos valles embellecidos con árboles y "verde hierba", y el aroma del tomillo, retama, cantueso y romero:

\footnotetext{
Mira cómo del alto Guadarrama ya por toda la falda y asperezas, entre los pinos y húmedas malezas, dividido en arroyos, se derrama, siguiendo un desigual despeñadero, el cúmulo de nieve que endureció en la cumbre el frío Enero, y el suave Abril liquida, mientras mueve el sol los ejes de oro
} 
hacia la celestial mansión del Toro.

Ya el pie de la montaña

y los profundos valles inmediatos

que deslizado aquel torrente baña,

mostrándose a tal riego nada ingratos,

tienden aquí de verde hierba alfombra;

allí visten sus árboles de ramas

que más fresca y opaca den la sombra.

Más allá los tomillos y retamas,

cantuesos y romeros,

por llanuras y oteros

exhalan aromáticos olores (vv. 148-68).

El poeta está desarrollando el gusto por las colinas, montañas y valles cubiertos de verdor, por la naturaleza misma, que ya no es símbolo o alegoría, sino que percibe envuelta en aromáticos olores y en suave canto de aves. Se siente un optimismo que "ilumina todo por igual, anega todo en esa luz aporcelanada que hace de las cosas algo poéticamente concreto e individual" según formula Casalduero (52).

Albano, que disfruta de una experiencia directa, describe vívidamente las ventajas materiales de la vida rústica que ofrece, a menos costo, deliciosas bebidas y manjares abundantes y sustanciosos. Recuerda los ricos almuerzos con nata, leche, miel y fresas "recién cogidas" ( $\mathrm{v}$. 313-17) y pinta el sueño reposado que aleja las preocupaciones del día.

El poeta se acerca generalmente a la naturaleza para disfrutar de su belleza y lograr un placer predominantemente estético. El estereotipo del paisaje descrito en fórmulas literarias muy conocidas no impide que a veces se rompan los tópicos convencionales para ofrecernos la pincelada fresca y novedosa de una visión directa de la naturaleza:

Un deleite recibe cuando tiende la vista por las fértiles campiñas, o de olivos pobladas o de viñas; otro, cuando suspende su atención en la margen festonada del arroyuelo manso, que desciende a regar una cañada, formando aquí un islote, allá un remanso, y lavando en sus aguas cristalinas el musgo, el césped y menudas chinas (vv. 115-24).

Cuando Albano trata de encontrar argumentos "más serios y eficaces" para convencer a Sileno de permanecer en la aldea, recurre a una reflexión de carácter religioso en que afirma la mayor proximidad de Dios en que viven los campesinos comparados con los hombres de la ciudad. Se trata de 
una concepción y sentimiento que podríamos llamar deísta, en que, tras admirar "la omnipotencia / del soberano Autor del universo" (v. 246), halla la mejor prueba de su existencia en la contemplación de las maravillas de la naturaleza:
¿No sientes cómo en él la omnipotencia
del soberano Autor del universo
respeto bien diverso
y gratitud más tierna nos inspira
que en las grandes ciudades? ¿Quién no admira
la sabia providencia
con que envía alternadas estaciones,
que al curso de los astros obedientes
vegetales renuevan a millones,
ocultos minerales y vivientes?
Elévate a las cumbres eminentes, y desde allí, con delicioso arrobo, un compendio verás de los portentos que suministra el espacioso globo al influjo de acordes elementos. Verás alegre el cielo despejado, y el terreno quebrado
en colinas, barrancos y laderas (vv. 245-62).

Desde su "rústico albergue" el labrador siente más inmediata la presencia y grandeza de Dios. La lógica de este argumento se funda en la consideración de que las verdades de la razón o de la naturaleza, como la percepción de Dios propia de los deístas, son universales y se revelan mejor al hombre primitivo y menos sofisticado que a las mentes más oscurecidas de prejuicios de los hombres cultos y civilizados (Lovejoy 86). Iriarte aplica apropiadamente el raciocinio a los habitantes de la aldea y de la ciudad. Guillermo Carnero interpreta de modo parecido un pasaje paralelo de Meléndez Valdés en "El filosofo en el campo", que pudo ser escrito en fechas próximas:

El deísmo instintivo es una de las razones de la superioridad moral de los campesinos que, por vivir en contacto directo con la Naturaleza, tienen una vivencia más intensa y limpia de la religiosidad (La cara oscura 81).

Si bien es cierto que ideas rousseaunianas están en el fondo de esta alta valoración moral de la vida campestre ${ }^{2}$, no es menos seguro que una cierta religiosidad difusa de origen deísta halla en el cambio de las estaciones, en las cumbres elevadas, en el cielo despejado y en los accidentes del

2. Paul Mérimée constata la temprana difusión de las ideas del Discours sur l'origine et le fondement de l'inégalité parmi les hommes (1754) de Rousseau, como se constata en varias publicaciones tempranas de la época (73). 
paisaje tantos testimonios portentosos del "Autor del universo". Esta visión de la extrema vastedad y de la fuerza abrumadora de la naturaleza contemplada desde las cumbres nos da una percepción de lo sublime como sensación de desbordamiento y de avance hacia la infinitud, a tono con la definición de Kant, que tan hondamente sobrecogía al hombre del siglo XVIII. Creo que pasajes como éste no hacen sino confirmar que el sentimiento de la naturaleza, liberado de los tópicos y expresiones consagradas de la tradición pastoril, "es uno de los rasgos más característicos de ese siglo XVIII emocional" de que habla Guillermo Carnero (La cara oscura, 83).

Pero la vida en plena naturaleza no sólo es bella y agradable. La Ilustración tiene de ella una visión utilitaria y el poeta subraya las comodidades, en cierto modo burguesas, que ésta aporta. Albano recuerda la confortable vida del campo en compañía de su consorte y en la abundancia de bienes materiales (vv. 5-8) y el solaz que cuerpo y alma encuentran en la soledad de la aldea (vv. 181-84). Alude a los ricos y sustanciosos manjares que la campiña ofrece, pero, de modo chocante, se queda (¿falta de viveza descriptiva? ¿Desconocimiento real del campo?) en meras formulaciones abstractas ("el manjar opulento y sustancioso") privándonos del placer estétitco de una pintura hecha con viveza y colorido. No obstante logra a veces cierta gracia en la presentación:

\author{
Allí no se escasea \\ la nata que separan \\ de la espumosa leche los vaqueros, \\ ni blanca miel de abejas, mantenidas \\ con la olorosa flor de los romeros, \\ ni fresas faltarán recién cogidas, \\ que una labradorcilla de quince años, \\ agradable y modesta, \\ traiga cubiertas de hoja en una cesta (vv. 312-20).
}

Una cierta aureola de belleza y hedonismo envuelve esta pintura de los objetos mencionados.

El poeta sigue describiendo el "plácido reposo" en "el catre dorado", el frescor de las mañanas al levantarse de madrugada y la robustez con que los niños se crían en el campo, por lo que las ilustres damas dan sus hijos para ser amamantados por las serranas (vv. 324-66). Pero tengo que confesar que Iriarte, en este largo pasaje y en otros en que pretende dar una tentadora visión de la vida de aldea, no logra sacudir cierta pesadez de estilo y tono abstracto, ni consigue la agilidad, colorido y viveza que piden tantos objetos bellos y útiles de la existencia rústica.

El poeta recuerda también otras "económicas tareas" como la cría de animales: cabras, ovejas, caballos, palomas y abejas, resaltando con orgullo su importancia capital como fundamental fuente de riqueza y base económica del orden social: 
$\mathrm{Ni}$ estos cuidados tengas por vileza,

pues no blasona el mundo

de otra mayor riqueza

que la que nace de un establo inmundo (vv. 471-74).

Precisamente esta faceta utilitaria de la visión de la naturaleza es una contribución muy propia del siglo XVIII. Jean-François de Saint-Lambert, que a su vez, como él mismo reconoce, se mueve en la tradición de James Thomson y Salomon Gessner, en sus poemas Les Saisons (1769) ayuda al despegue de la clásica tradición arcádica de pura ficción hacia una naturaleza real y útil a los hombres, percibida con enfoque científico, humanitario y filosófico. Saint-Lambert dice en su Discours préliminaire que la poesía debe proponerse conmover y "graver dans le coeur et la mémoire des hommes des verités et des sentiments utiles ou agréables" (De Nardis 128) y en la estación Le printemps formula en versos rotundos su principio:

Le beau ne plait qu'un jour, si le beau n'est utile...

Oh! que j'aime bien mieux cet utile jardin où l'art, en se cachant, subjugue le terrain, prodigue la richesse...(De Nardis XI-XII).

Se puede suponer que el poeta canario, buen desgustador de la cultura francesa, conoció Les Saisons de Saint-Lambert ${ }^{3}$.

\section{Valoración: La Égloga y su tiempo}

Para mejor entender nuestras observaciones sobre la Égloga del poeta canario, conviene aclarar que la composición bucólica no es el género que mejor responde a los intereses de los Ilustrados. Los temas filosóficos, científicos y éticos, son las grandespreocupaciones de la poesía dieciochesca en la época de Carlos III. Jovellanos, en su epístola a sus amigos de Salamanca, escrita en 1776 , se confiesa fatigado de la canción personal y lírica ("Y no extrañéis que del eolio canto / cansada ya su musa") y se convierte "al compás lento y numeroso" de la poesía didáctica (IV, 205). Si anima a Delio a consagrar su inspiración "a la moral filosofía" y a cantar "los estragos del vicio", a Batilo (Meléndez Valdés), el gran poeta bucólico, lo invita a abandonar "el caramillo pastoril" ya adoptar un tono más ejemplar y épico: "la sonante / trompa para entonar ilustres hechos" (IV,

3. Tal vez haya un indicio de ello en la coincidencia de ambos en designar los tiempos del año por la alusión a las doce regiones del zodíaco: "A Cáncer da las lluvias de Acuario / y el calor del León al Sagitario" (vv. 34-35); "mientras mueve / el sol los ejes de oro / hacia la celestial mansión del Toro" (vv. 155-57). Algo parecido hace frecuentemente Saint-Lambert: "Dejà près du cancer le soleil est monté" (De Nardis XV); "Mais voici le moment où l'astre des saisons / arrive du cancer au Lion de Némée" (De Nardis XXVII). 
211). Por ello no nos extraña que el juego elegante de la vida pastoril que evoca Iriarte no se quede en pura frivolidad, sino que se impregne de sentimientos morales, filosóficos y religiosos, y se convierta en marco donde se encuadran preocupaciones muy propias de aquel momento de la Ilustración. La expresión poética de un acercamiento a la naturaleza, matizado con ideas filosóficas rousseaunianas o religiosas de resonancias deístas, se funde con propósitos utilitarios y patrióticos.

Iriarte está condenando, por boca de Albano, a aquellos que se dejan deslumbrar por "el ostentoso porte", "la brillante apariencia de las galas", "la superflua compostura", "la vana exterior magnificiencia" y "el desmedido lujo" de la corte, marchándose a las ciudades y exponiendo sus familias a la ruina: "¡A qué desorden tu familia expones!". Exhorta a que no abandone el traje y la honrada profesión de sus mayores, que siempre aquí residieron: "Esta aldea fue siempre su morada" (vv. 367-98). Le invita a consagrarse a la labranza, la siembra, la siega, la poda, la vendimia, la cría de animales y al trabajo, precepto que impuso el Criador a los mortales: "Y en que de una nación la dicha estriba" (vv. 433-74). Iriarte, en cuya conciencia actúa la preocupación por los vastos problemas de la agricultura y de la nación, proclama la importancia de criar "hijos, laboriosos / y útiles a la patria" (vv. 386-87), y de consagrarse a la producción agrícola, la mayor fuente de riqueza de que disponen los pueblos (vv. 473-74). Tal afirmación, vagamente, se hace eco de las ideas de la escuela fisiocrática y del Tableau Economique de François Quesnay, aparecido en 1758, que logró gran difusión y éxito hasta la aparición de la Inquiry into the nature and causes of the wealth of the nations de Adam Smith en 1776.

El historiador y economista Pedro Voltes subraya ese protagonismo que se concedía a la agricultura. Junto con la libre circulación de productos, todos la exaltan como panacea de todas las penurias:

Del Rey abajo, España entera está galvanizada por el anhelo de multiplicar la riqueza del país [...] Todos los españoles echan cuentas y están transidos de preocupaciones económicas (Carlos III 143, 147).

Las sociedades de Amigos del país, los centros de estudio, los intelectuales y los funcionarios, rivalizarán en entusiasmo por exaltar la agricultura y proponer medios para mejorarla (Historia 332).

Jovøllanos considera evidente la función básica de la agricultura en el proceso económico:

¿Puede dudarse que en todos sentidos sea la agricultura la primera base de la industria, del comercio y de la navegación? ¿Quién, sino ella, produce las materias a que da forma la industria, movimiento el comercio y consumo la navegación? ¿Quién, sino ella, presta los brazos que continuamente sirven y enriquecen a otras profesiones? (Informe 149-50). 
Así piensa también Campomanes cuando asegura que "aunque son necesarios los oficios, es más provechosa la agricultura" (Voltes, Historia 332). Se trataba de un "movimiento de retorno a la tierra, de interés por el campo, donde se conjugaban, en apagado eco, las novedades agrarias británicas, la fisiocracia francesa y el naturalismo de Rousseau" (Domínguez Ortiz, Sociedad 410).

En esta postura progresista e ilustrada se mueve Iriarte. El poeta canario, sensible a hondas preocupaciones de su siglo, está aludiendo a un serio problema que va a denunciar en páginas brillantes: la huida del campo y el absentismo de ciertos propietarios, endémicos males económicos y agrícolas tan vivamente evocados por Jovellanos en su Informe sobre la ley agraria cuando habla de los cerramientos:

¡Y qué! ¿Pudiera el gobierno hallar un medio más sencillo, más eficaz, más compatible con la libertad natural, para atraer a sus tierras y labranzas esta muchedumbre de propietarios de mediana fortuna, que amontonados en la corte y en las grandes capitales perecen en ellas a manos de la corrupción y el lujo; esta turba de hombres miserables e ilusos que, huyendo de la felicidad que los llama en sus campos, van a buscarla donde no existe, y a fuerza de competir en ostentación con las familias opulentas labran en pocos años su confusión, su ruina y la de sus inocentes familias? (Informe 56-57).

Iriarte no se ha entregado a un evasivo utopismo pastoril. Y quiero con ello mostrar mi desacuerdo con la generalización que formula De la Flor:

La pastoral de este tiempo vehicula en consecuencia más ideología vinculada al humanismo agrícola, a la pia rusticitas, a la santa Agricultura de los tratadistas renacentistas, que al espíritu del Informe librado por Jovellanos (138).

El poeta canario está situando su égloga en esferas próximas a la realidad socio-económica. Señala el frecuente abandono de tierras cultivadas que hacía exclamar a Jovellanos: "Tantas tierras sin hombres y tantos hombres sin tierras" (Domínguez Ortiz, Sociedad 411). La huida de los campos hacia los centros urbanos, donde tantas familias se hundían en la pobreza y miseria moral creando un serio problema económico, merece su llamada de atención. "Los economistas del siglo XVIII -dice G. Anes Álvarez- seguían quejándose de la despoblación de las zonas rurales" (Economía 15). Así lo percibía también el gobierno. Iriarte recuerda al "magnánimo Carlos" y su política de liberalización y supresión de tasas que culmina en el "reglamento promulgado por Carlos III en el 12 de octubre de 1778 para el comercio libre de España con sus Indias" (Voltes, Carlos III 148), del cual espera grandes beneficios para los labradores, ya que fomentará la industria, la navegación y las exportaciones, dando más fácil salidad a los productos del campo: 


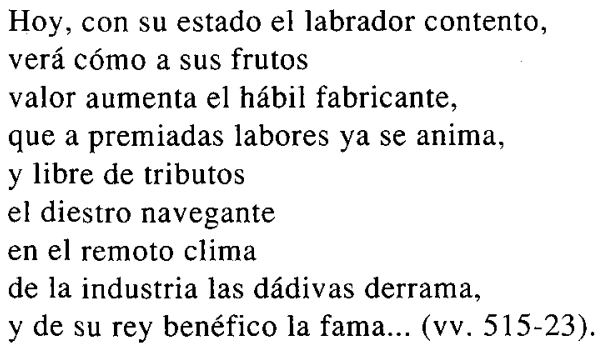

La Égloga se ha convertido en caja de resonancia de cuestiones económicas urgentes y de preocupaciones muy propias de su tiempo.

Y no nos debe extrañar esto, ya que Iriarte está siendo consecuente con las concepciones estéticas que él mismo define en esta obra (v. 211-16). El criterio de la verdad es predominante en toda su creación poética. Los ambientes de la vieja tradición pastoril se han convertido en bello entorno para prestar relieve a los valores más reales y hondos de la Ilustración:

La obsesión de Iriarte - dice Joaquín Arce- es la verdad y la claridad: la verdad adornada se convertirá en una reiteración del utile dulci, manifiestamente expresado en la fábula XLIX, El jardinero y su amo... "Si al pleno acierto aspiras / une la utilidad con el deleite" (Arce 266).

Verdad, sobre todo, deseo de instruir e inquietud por promover la utilidad y el bien público como altos ideales de la Ilustración ${ }^{4}$.

Es cierto que Tomás de Iriarte no muestra en su obra verdadera conciencia de la situación mísera del campesino, ni propone una reforma social de tipo rousseauniano. En el único pasaje en que a ello alude lo hace por boca de Sileno, aldeano fascinado por los encantos de la ciudad. Denuncia más bien lo penosa e ignorada que es la vida de aldea, las duras labores del campo bajo los climas más severos y la inseguridad de la cosecha por causa de las inclemencias atmosféricas:
¿Ignoras tú del mísero aldeano
cuán penosa es la vida, cuán obscura?
¿Quién le conoce, dime, quién le estima
después que, resistiendo
a la intemperie del variable clima,

4. A pesar de que según Krömer (151), lo único que se discutía en el siglo XVIII era si "la utilidad es incondicionalmente necesaria" ("ob der Nutzen unbedingt nötig ist"), él mismo reconoce la gran importancia que en general se le prestaba. Algunos (Le Bossu, Forner) querían convertir al poeta en un filósofo y moralista; Forner cree que la poesía siempre es enseñanza y Luzán dice que hay también poesía "que no entretiene,sino sólo enseña" (die nicht unterhält, sondern nur belehrt). 
riega con su sudor la tierra dura, y cuando espera frutos, el horrendo estrépito del trueno le amedrenta amenazando estragos a las mieses, o el infeliz al cielo se lamenta de que, alterando el orden de los meses, a Cáncer da las lluvias del Acuario y el calor del León al Sagitario?...

Sí, Albano; recibieron del destino, la aldea afanes, y la corte gustos (vv. 23-46).

Pero el mismo Sileno, tras escuchar las sabias razones de Albano, cierra la égloga recordando "al monarca piadoso / por quien felices son los labradores" (vv. 556-57), e invocando, optativamente, la visión de una agricultura sin problemas bajo el rey reformador, muy lejos de las denuncias de Jovellanos y de Mélendez Valdés.

La Égloga de Iriarte pertenece al género pastoril por decisión del mismo autor. De los dos elementos que De la Flor considera esenciales a la estructura de la poesía bucólica, la "recuperación de la clasicidad" partiendo de un género de tendencia utópica y la ambientación en "los nuevos tiempos" (145), el poeta canario, en una línea que nos recuerda a James Thomson, Salomon Gessner y Saint-Lambert, logra una inserción del hombre sensible, social y filósofo en el paisaje y consigue captar aspectos sustanciales y decisivos del momento histórico que está viviendo. Russell Sebold observa que Iriarte, "hombre de una fina sensibilidad histórica" se daba perfecta cuenta de la imposibilidad de triunfar en el género épico, ya que las grandes aventuras de su siglo no eran militares sino científicas. También debía ser consciente "del agotamiento artístico de la égloga" ( $E l$ rapto 235-36). Por ello se dirige a problemas reales que el espíritu ético y utilitario dieciochesco le hace sentir como urgentes y que él logra formular con vigor y viveza. La imagen que Juan L. Alborg nos ofrece de Iriarte como "un gourmet del arte, un delicado catador de excelencias, que ridiculiza el mundo de la gente vulgar" y el autor de un tipo de sátira "suave y correcta" (ya que "un cortesano nunca se descompone") la completa con los cumplidos de su estilo: "tersura, elegancia, matices delicados, agudeza crítica, precisión, lenguaje implecable, dominio completo del instrumento que se maneja" (529). Pero quedaría desdibujada la imagen de Tomás de Iriarte si no recordáramos, además de su deseo de enseñar, que le lleva a la fábula, esta conciencia y preocupación por el bienestar y progreso de la nación y esta función ilustradora y científica que también sabe prestar a su poesía como ampliamente logra probar en esta Égloga. 


\section{OBRAS CITADAS}

Alborg, Juan Luis. Historia de la literatura española, III.Siglo XVIII, Madrid, Gredos, 1972.

Anes Álvarez, Gonzalo. Economía e 'Ilustración' en la España del siglo XVIII, Esplugues de LLobregat, Ariel, 1969.

Arce, Joaquín. La poesía del siglo ilustrado, Madrid, Alhambra, 1981.

Blumemberg, Hans. "Wirklichkeitsbegriff und Möglichkeit des Romans".

Nachahmung und Illusion, ed. H. R. Jauss, München, Wilhelm Fink Verlag, 1969.

Carnero, Guillermo. La cara oscura del siglo de las luces, Madrid, Cátedra, 1983.

Casalduero, Joaquín. "Las nuevas ideas económicas sobre la agricultura en el siglo XVIII y el nuevo sentimiento de la naturaleza", La Torre 61 (1968), 45-60.

Cotarelo y Mori, Emilio. Iriarte y su época, Madrid, Sucesores de Rivadeneyra, 1897.

De Cueto, Leopoldo Augusto. Poetas líricos del siglo XVIII, II. Madrid, BAE, vol. 63, 1871.

De la Flor, Fernando R. "Arcadia y Edad de Oro en la configuración de la bucólica dieciochesca", Anales de Literatura española, 2, (1983), 133-53.

De Nardis, Luigi. Saint-Lambert: scienza e paesaggio nella poesia del settecento, Roma, Edizioni dell'Ateneo, 1981.

Dominguez, Ortiz, Antonio. Sociedad y estado en el siglo XVIII español, Barcelona, Ariel, 1976.

García Berrio, Antonio. Formación de la teoría literaria moderna, Madrid, Cupsa, 1977.

Giamatti, A. Bartlett. The Esrthley Paradise and the Renaissance Epic, Princenton University Press, 1969.

Iriarte, Tomás de. Obra poética, Leopoldo Augusto de Cueto, ed., Poetas líricos del siglo XVIII, II, Madrid, BAE, vol. 63, 1871.

Jovellanos, Gaspar Melchor. Informe sobre la ley agraria, ed., J. C. Acerete, Barcelona, Ed. de Materiales, 1968.

- Obras, vol. IV, Madrid, Mellado, 1846.

Krömer, Wolfran. Zur Weltanschauung, Ästhetik und Poetik des Neoklassizismus und der Romantik in Spanien, Münster Westfalen, Aschendorffsche Verlagsbuchhandlung, 1968.

López Estrada, Francisco. Los libros de pastores de la literatura española, Madrid, Gredos, 1974. 
Lovejoy, Arthur Oncken. "The Parallel of Deism and Classicism" en Essays in the History of Ideas, New York, G. Braziller, Inc., 1955, $78-98$.

Luzán, Ignacio de. La poética o reglas de la poesía en general y de sus principales especies, Zaragoza, 1737.

Mérimée, Paul. L'influence française en Espagne au dix-huitième siècle, Paris, Les Belles Lettres, s. a.

Navarro González, Alberto. "Temas humanos en la poesía de Iriarte", Revista de Literatura, 1 (1952), 7-24.

Sebold, Russell P. El rapto de la mente, Barcelona, Anthropos, 1989. - Descubrimiento y fronteras del neoclasicismo español, Madrid, Cátedra, 1985.

Voltes, Pedro. Carlos III y su tiempo, Barcelona, Juventud, 1964.

- Historia de la economía española hasta 1800, Madrid, Ed. Nacional, 1972. 